\title{
Stress Rupture Testing and Analysis of the NASA WSTF-JPL Carbon Overwrapped Pressure Vessels
}

\author{
Nathanael Greene, ${ }^{1}$ Tommy Yoder, ${ }^{2}$ and Regor Saulsberry ${ }^{3}$ \\ NASA Johnson Space Center White Sands Test Facility, Las Cruces, NM 88004 \\ Lorie Grimes-Ledesma ${ }^{4}$ \\ NASA Jet Propulsion Laboratory, Pasadena, California, 91109 \\ John Thesken ${ }^{5}$ \\ Glenn Research Center - Ohio Aerospace Institute, Cleveland ,Ohio, 44135 \\ and \\ S. Leigh Phoenix ${ }^{6}$ \\ Cornell University, Ithaca, New York, 14853
}

\begin{abstract}
[Abstract] Carbon composite overwrapped pressure vessels (COPVs) are widely used in applications from spacecraft to life support. COPVs are used primarily for propellant storage and actuation pressure storage. COPV technology provides a pressurized media storage advantage over amorphous technology with weight savings on the order of $\mathbf{3 0}$ percent. The National Aeronautics and Space Administration (NASA) has been supporting the development of this technology since the early $1970 \mathrm{~s}^{\mathrm{i}}$ with an interest in safe application of these components to reduce mass to orbital insertion and on orbit. NASA White Sands Test Facility (WSTF) has been testing components in support of this objective since the 1980s and has been involved in test development and analysis to address effects of impact, propellant and cryogenic fluids exposure on $\operatorname{Kevlar}^{\circledR}$ and carbon epoxy ${ }^{\text {ii }}$ structures.
\end{abstract}

The focus of this paper is to present results of a recent joint WSTF-Jet Propulsion Laboratories (JPL) effort to assess safe life of these components. The WSTF-JPL test articles consisted of an aluminum liner and a carbon fiber overwrap in an industry standard epoxy resin system. The vessels were specifically designed with one plus-minus helical wrap and one hoop wrap over the helical and they measured $4.23 \varnothing \times 11.4$-in. long. One hundred and twenty test articles were manufactured in August of 1998 of one lot fiber (T-1000) and resin and the 110 test articles were delivered to WSTF for test. Ten of the 120 test articles were burst tested at the manufacturer to establish the delivered fiber stress. Figure 1 shows a test article in a pre burst condition and with a hoop fiber failure (no leak of pressurized media) and post burst (failure of liner and loss of pressurized media).

\footnotetext{
${ }^{1}$ Project Manager. RF/NASA Laboratories Office, PO Box 20, Las Cruces, New Mexico, 88004.

${ }^{2}$ Project Engineer, NASA Laboratories Office PO Box 20, Las Cruces, New Mexico, 88004.

${ }^{3}$ Project Manager. RF/NASA Laboratories Office, PO Box 20, Las Cruces, NM, 88004.

${ }^{4}$ Project Engineer, Propulsion and Materials Engineering, NASA Jet Propulsion Laboratory, Pasadena, California, 91109.

${ }^{5}$ Team Manager, Life Prediction Branch, Glenn Research Center - Ohio Aerospace Institute, Cleveland, Ohio, 44135.

${ }^{6}$ Professor, Theoretical and Applied Mechanics, Cornell University, Ithaca, New York, 14853.
} 


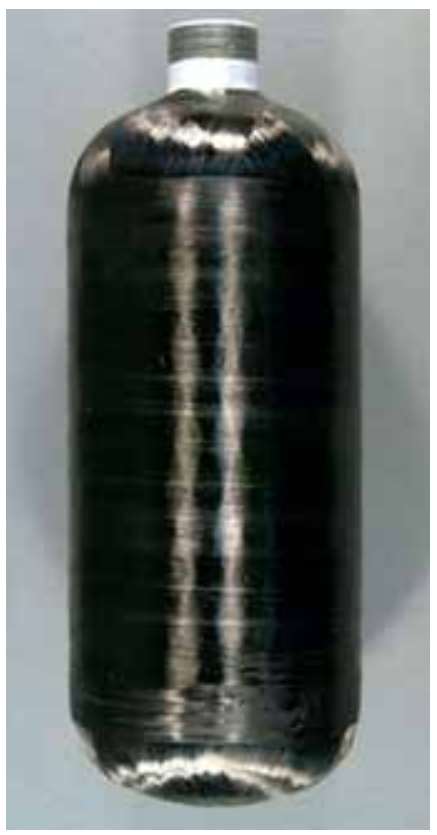

wstf0106e00088

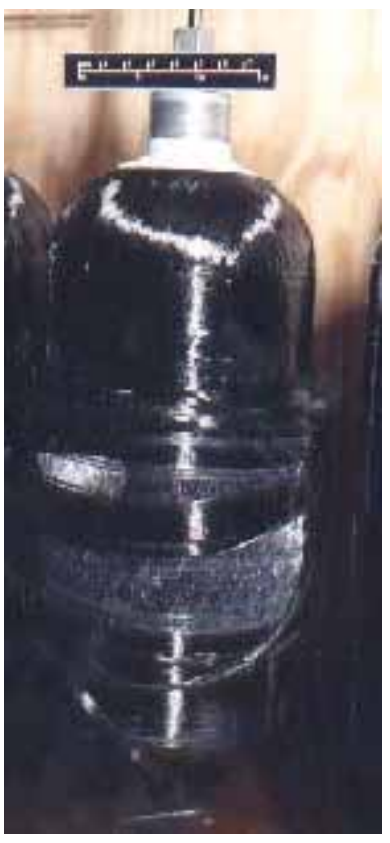

wstf0899-1474

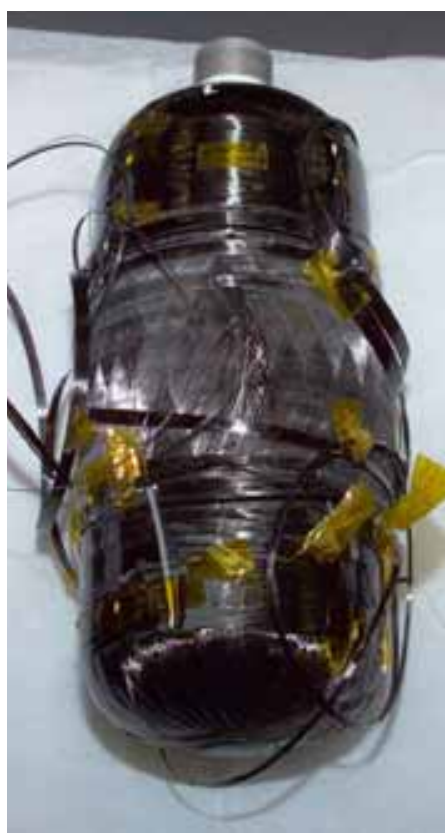

wstf1004e9247

Figure 1. WSTF-JPL Test Article (left to right) before Pressurization, in Test with a "Hoop Tow Failure" and after a "Burst Failure"

A sample of 73 test articles have been placed into stress rupture testing to date with achieved pressure ratios of 93.3, 91.2, 91.0, 88.7, 87.5, 87.2, 86.4, and 74.6 percent based on the average burst pressure of the 20 initial burst tests. Three test articles burst on pressurization or early in stress rupture at unexpected times and pressures. Expected times and pressures for failure were established before test using an industry standard mode ${ }^{\mathrm{iii}}$, iv based on carbon epoxy strand test results. Fiber stress ratios were provided from the manufacturer and were used to set target stress levels. A later NESC assessment of stress ratios showed that actual fiber stresses in test were up to 11 percent higher than the fiber stress that was provided. A higher fiber stress ratio at burst brought results closer to model predictions; however, this was not sufficient to explain the unexpected failures. Figure 2 compares the original and the corrected fiber stress ratios.

The vessels were specially designed with a hoop wrap over the helical wrap to force failure in the hoop wraps. During test, the hoop tows would be observed to fail and unraveling of the overwrap would occur as is shown in Figure 1. Failures were noted to occur in the hoop region of the COPV. Modeling showed that all but the S/N 2141 failure at 3200 psi could be explained by the statistics of strand failure. A full investigation into the causes of the failures are discussed in a companion paper titled, Unexpected Shelf-life Degradation Phenomenon of the WSTF-JPL Carbon COPV Test Articles: An Analysis and Independent Assessment. ${ }^{\mathrm{v}}$ and the NASA Engineering Safety Center Report. ${ }^{\mathrm{vi}}$

The test articles were placed into test systems consisting of nine test articles each, connected by a manifold and pressurized simultaneously. Tests were run at pressure ratios based on a percentage of the burst pressure value. Four test articles from various groups either did not make test pressure or failed much more quickly than expected at test pressure. This outcome from testing resulted in a white paper and an investigation initiated by NESC. Figure 3 shows views of one of the STEB stress rupture test facilities. Table 1 contains WSTF-JPL COPV data.

Two types of COPV failure were observed to occur during testing. The first type was when a strand of fiber was observed to break and begin to unwind from the hoop region of the COPV. This type of failure of the overwrap did not compromise the liner or cause loss of pressure in the test article. Failures of this type were noted as "hoop" failures. The test continued until the second type of failure occurred in that test group. The second type was a "burst" failure, where the liner was compromised resulting in loss of pressure and observation of fiber failure. This type of failure ended the testing.

The results of this testing have provided valuable information on how to test carbon COPVs. It was noted that these COPVs were specifically designed to fail in the hoop region and most flight pressurant COPVs are not of similar design. COPVs of this design lack significant layers of over-wrap to adequately distribute load throughout the entire structure. Testing of similar components is important in accurately assessing life, although budgets can be 
a constraint. Also, an observation was made that vigilance is needed in reviewing manufacturer reports and operational stress conditions for a COPV. Stress ratio should be understood by the test engineer previous to placing vessels on test.

The vessels tested in the WSTF-JPL program did not have high quality controls during manufacture. Visually, the vessels varied in appearance. There were indications of grinding and variation in resin content from vessel to vessel. Burst testing was performed to identify how manufacturing variations would affect vessel strength and no statistical difference in burst strength was found in the worst vessels from a resin grinding perspective. The pressurization rate for burst testing was much faster than the pressurization rate used to place the vessels into stress rupture. A slower pressurization rate for burst testing may identify manufacturing variation due to additional time allowed for the tow unraveling process.

The WSTF-JPL vessel failures were earlier than any model would have predicted. A new model was developed by the NESC assessment team that modeled the vessels as a strand test with a long gauge length. This model fit all but the failure of S/N 2141. The failure of S/N 2141 on pressurization may be due to a combination of manufacturing variation and the strand like behavior of the hoop wound structure.

Exposed-dome hoop wound COPVs have been flight qualified and are in use for space flight applications. These hoop wound structures are expected to be more sensitive to manufacturing variations than a thicker overwrapped COPV with heavy interweaving of the overwrap patterns. Stress rupture data for flight qualified hoop wound vessels is needed to determine if stress rupture models are conservative in thin hoop wound applications.

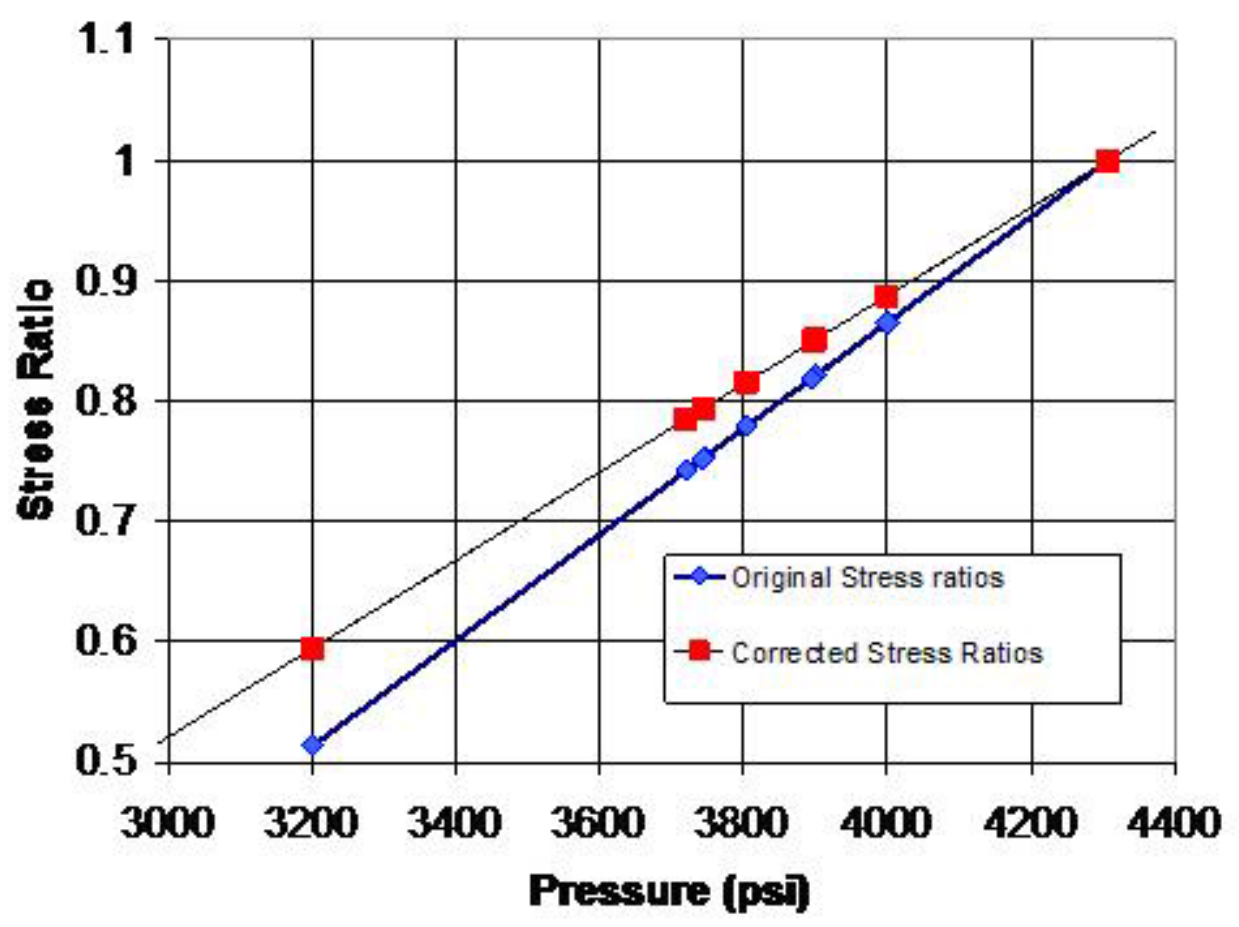

Figure 2. Stress Rupture Chart for WSTF-JPL COPVs 

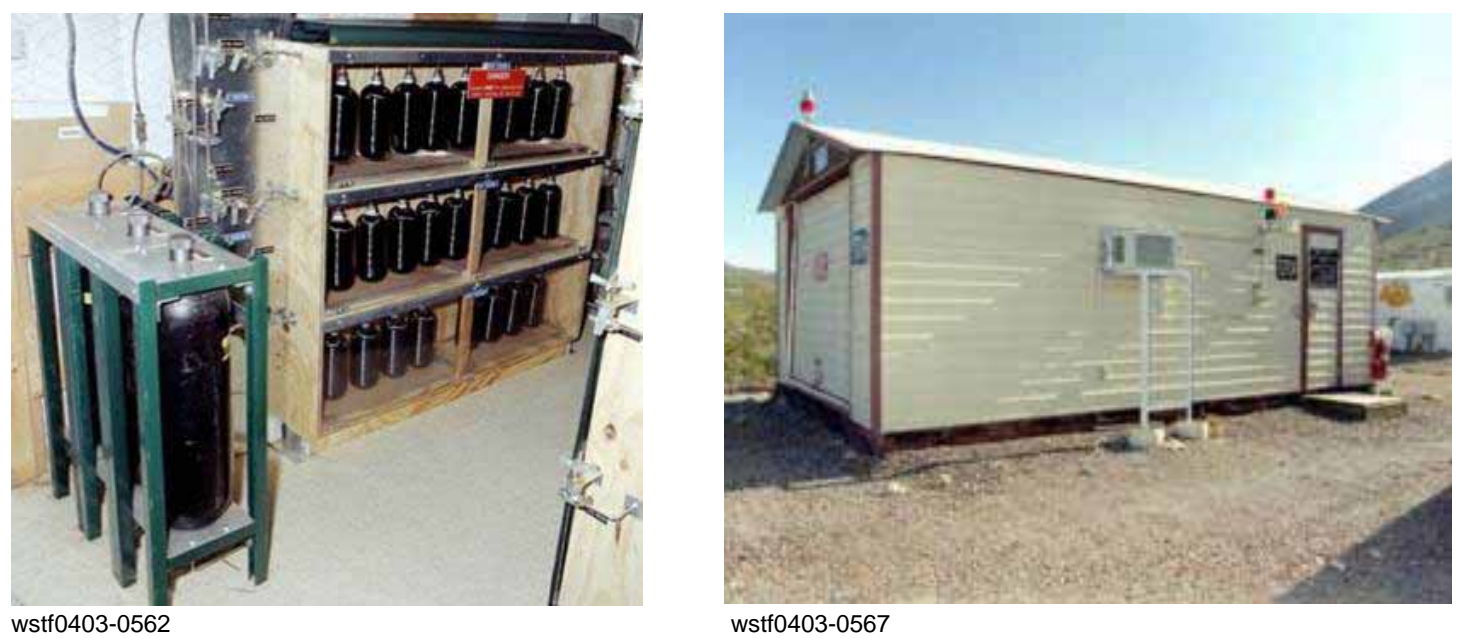

Figure 3. Carbon Epoxy Three-bank Test System with Accumulator and Stress Rupture Test Facility

Table 1. WSTF-JPL COPV Information

\begin{tabular}{l|l}
\hline Luxfer Standard Test and Experiment Bottle Specifications \\
\hline Mean Burst Pressure & $4288 \pm 115 \mathrm{psi}$ \\
Service Pressure & $3000 \mathrm{psi}$ \\
Dimensions & $4.23 \emptyset$ x 11.4 L \\
\hline
\end{tabular}

\section{References}

${ }^{\mathrm{i}}$ Lark, R. F. “Recent Advances in Lightweight, Filament-wound Composite Pressure Vessel Technology,” NASA TM-73699, 1977.

ii Beeson, H., D. Davis, W. R. Ross, and R. Tapphorn. “Composite Overwrapped Pressure Vessels,” NASA Technical Paper, TP-2002-210769, Johnson Space Center, Houston, Texas, January 2002.

iiiiThomas, D. A. "Long-life Assessment of Graphite/Epoxy Materials for Space Station Freedom Pressure Vessels,” AIAA Journal of Propulsion and Power, Vol. 8., No. 1., 1992.

${ }^{\text {iv } G r i m e s-L e d e s m a, ~ L . ~ a n d ~ H . ~ W . ~ B a b e l . ~ " C o m p a r i s o n ~ o f ~ S t r e s s-R u p t u r e ~ L i f e ~ P r e d i c t i o n ~ T e c h n i q u e s ~ f o r ~}$ Composite Pressure Vessels," Proceedings of the $51^{\text {st }}$ International Astronautical Congress, Rio de Janeiro, Brazil, October 2-6, 2000.

${ }^{\mathrm{v}}$ Murthy, Pappu L. N., K. Cameron, J. Thesken, J. K. Sutter, N. Greene, R. Saulsberry, L. Phoenix and L. Grimes-Ledesma. "Unexpected Shelf-life Degradation Phenomenon of the WSTF-JPL Carbon COPV Test Articles: An Analysis and Independent Assessment.” Proceedings of the AIAA SDM Conference, Hawaii, April 23-26, 2006.

vi، Shelf-life Phenomenon for Graphite/Epoxy Overwrapped Pressure Vessels (COPV) Technical Consultation Report,” NASA Engineering and Safety Center, Report \#04-009, COPV ITA. 


\section{STRESS RUPTURE TESTING AND ANALYSIS OF THE NASA WSTF- JPL CARBON OVERWRAPPED PRESSURE VESSELS}

Program Manager: Dr. Harold Beeson

Project Leader: Tommy Yoder

Date: April 26, 2007 


\section{Stress Rupture Study Program}

The objective of the program is to determine the safe application of Composite Overwrapped Pressure Vessels (COPVs) with respect to stress rupture. 


\section{Background of COPVs}

- Composite Overwrapped Pressure Vessel: Filament wound fibers over thin metal shell offer a high strength to weight ratio

- Reduce mass for both orbital insertion and on-orbit.

- Application saves up to 30-percent weight.

- Originally metal and/or glass fiber

- Replaced initially with Kevlar fiber

- Commonly Carbon fiber

- New materials (Zylon and Hybrid design) 


\section{Approach to Stress Rupture Testing}

- Program modeled mid-1990s WSTF COPV impact study of Gr/Ep COPVs

- Apply various pretest NDE

- Impact COPV with instrumented mechanical impact tester

- Apply posttest NDE

- Burst test COPV

- Correlate results to similar Gr/Ep COPVs 


\section{Stress Rupture Facility}

- Modified Morgan Building

- HVAC control (control to $\pm 5^{\circ} \mathrm{F}$ dead band, \pm 2 degrees nominal)

- Watch-dog system 


\section{Test System}

- Banks of nine STEB test articles

- Liquid-locked pressure system

- Accumulators to reduce pressure fluctuations

- Pressure Transducer with data logger 


\section{Pressure Test Systems}

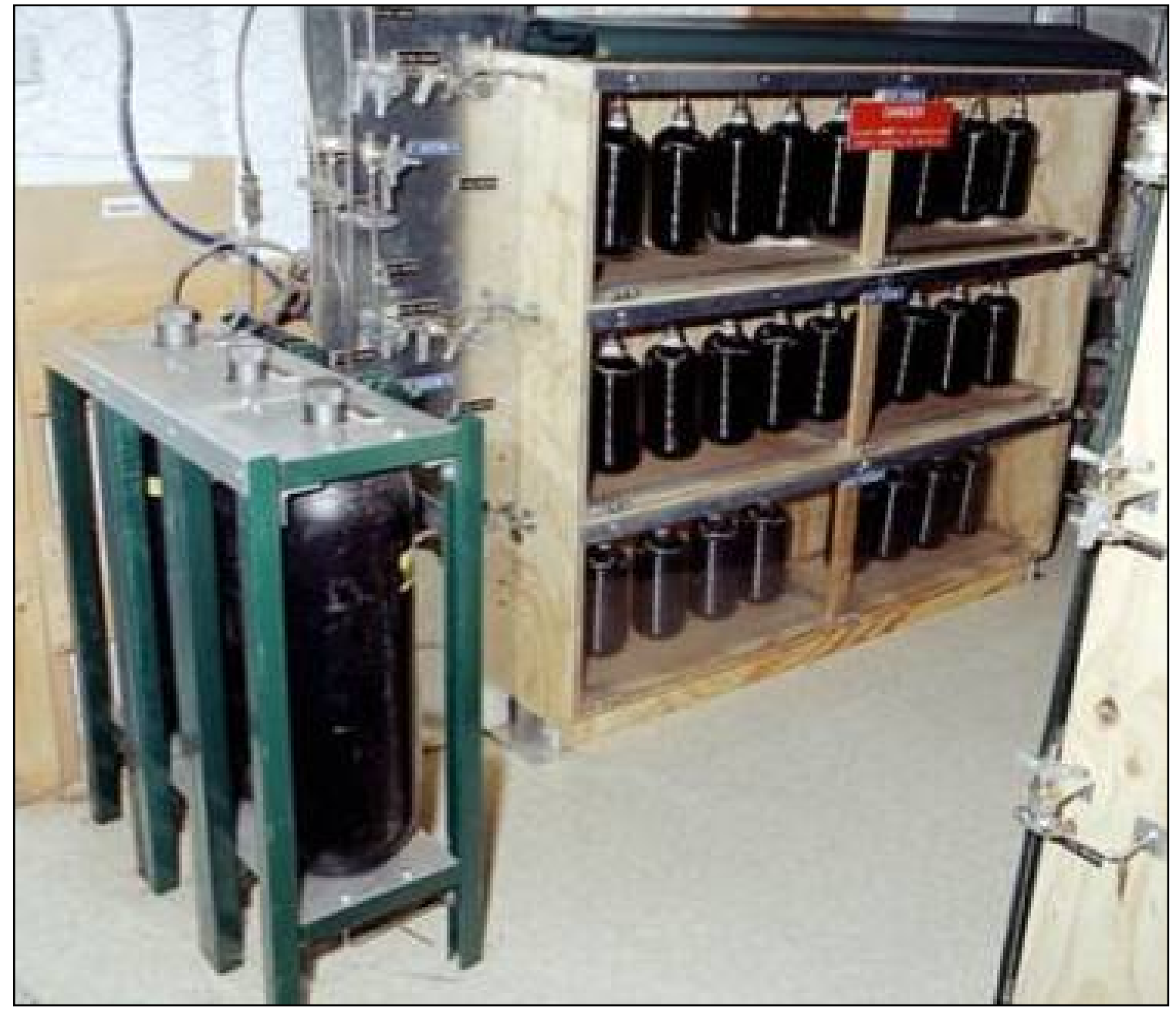




\section{Issues with Test Articles}

- Relatively thick-walled liners

- Load sharing causes question with actual stress ratio

- Only tow wrap patterns (three layers)

- True composite structure/load sharing

- Mechanical damage to composite

- Cleared by burst test, increased scatter 


\section{Failure Observations}

- Hoop wrap failures (tow failures to catastrophic vessel failure - loss of pressure)

- Tow splitting observed in most cases prior to catastrophic failure

- Lifting of tow wrap 


\section{Typical Failures}
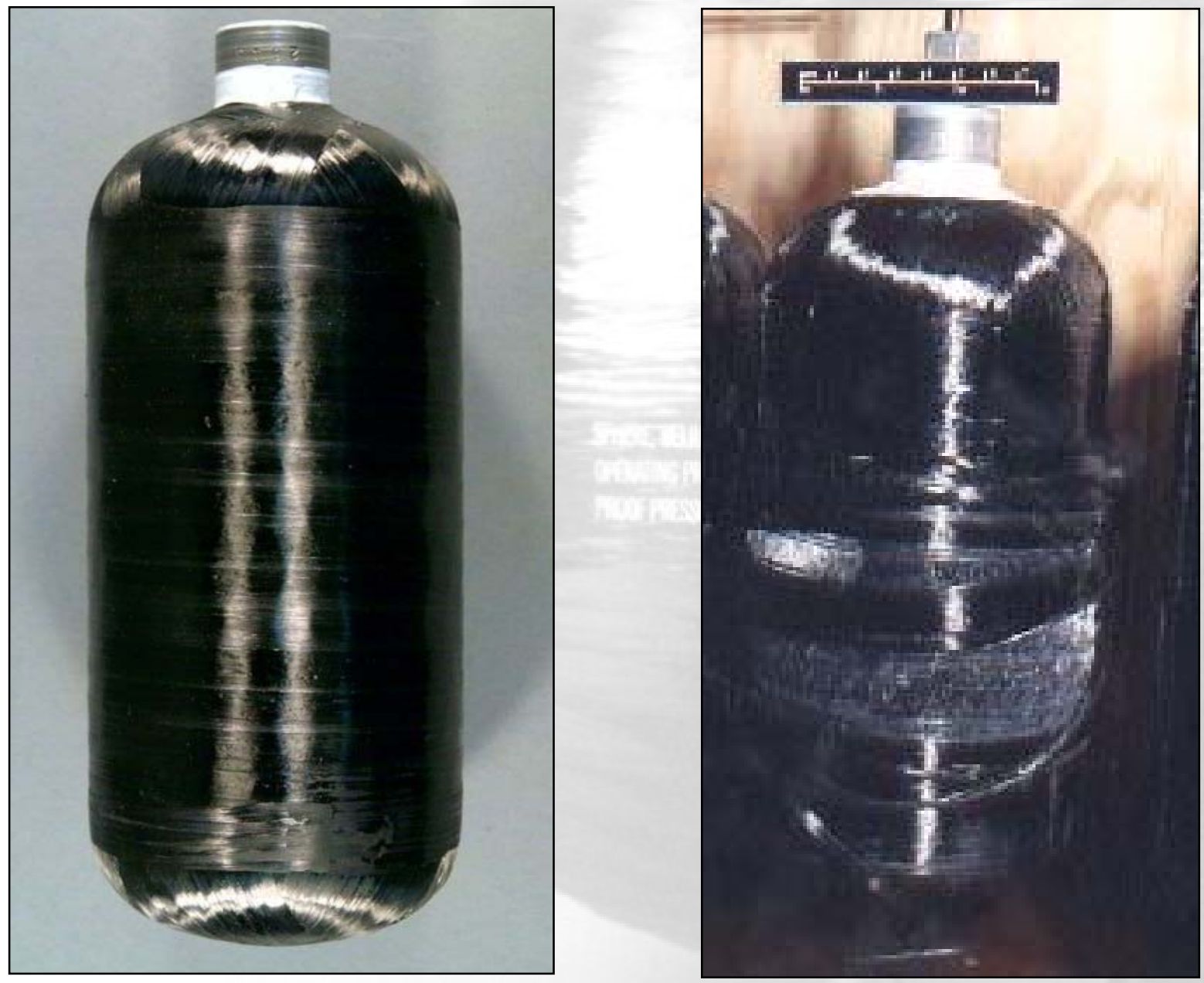


\section{Results of Stress Rupture Testing}

- To date, 73 test articles have been placed into stress rupture testing

- Stress ratios from 93.3 to74.6 percent

- Experienced unexpected failures times and pressures

- NESC assessment of stress ratios showed actual fiber stresses were up to 11 percent higher than fiber stress provided

- Results closer to model predictions; not sufficient to explain the unexpected failures 


\section{In Conclusion}

- Provided valuable information on how to test carbon COPVs

- Design lacks significant layers of overwrap to adequately distribute load throughout the entire structure

- Vigilance needed in reviewing manufacturer reports and operational stress conditions for a given COPV design 